\title{
Isolation and identification of exosomes from feline plasma, urine and adipose- derived mesenchymal stem cells
}

Dongsheng $\mathrm{Li}^{1+}$, Huina Luo ${ }^{2 \dagger}$, Huimin Ruan ${ }^{1}$, Zhisheng Chen ${ }^{2}$, Shengfeng Chen ${ }^{2}$, Bingyun Wang ${ }^{1,2^{*}}$ and Yong $\mathrm{Xie}^{3^{*}}$

\begin{abstract}
Background: Exosomes, internal proteins, lipids, and nucleic acids coated by phospholipid bilayer membranes, are one type of small extracellular vesicles, which can mediate cell-cell communication. In recent years, exosomes have gained considerable scientific interest due to their widely applied prospect in the diagnosis and therapeutics of human and animal diseases. In this study, we describe for the first time a feasible method designed to isolate and characterize exosomes from feline plasma, urine and adipose-derived mesenchymal stem cells.

Results: Exosomes from feline plasma, urine and adipose-derived mesenchymal stem cells were successfully isolated by differential centrifugation. Quantification and sizing of exosomes were assessed by transmission electron microscopy, flow nano analysis and western blotting. Detected particles showed the normal size $(30-100 \mathrm{~nm})$ and morphology described for exosomes, as well as presence of the transmembrane protein (TSG101, CD9, CD63, and CD81) known as exosomal marker.

Conclusions: The results suggest that differential centrifugation is a feasible method for isolation of exosomes from different types of feline samples. Moreover, these exosomes can be used to further diagnosis and therapeutics in veterinary pre-clinical and clinical studies.
\end{abstract}

Keywords: Feline, Exosomes, Mesenchymal stem cells, Plasma, Urine, Nanoparticle

\section{Background}

Exosomes, extracellular vesicles with a diameter of 30$120 \mathrm{~nm}$, widely present in body fluids such as blood [1], saliva [2], cerebrospinal fluid [3], urine [4], milk [5], semen [6] and synovial fluid [7]. Exosomes deliver rich nucleic acid, protein and lipid content and participat in cell-to-cell communication [8, 9]. Exosomes are increasingly considered as biomarkers and prognostic factors of

\footnotetext{
*Correspondence: bywang63@163.com; whitefox2013@163.com ${ }^{\dagger}$ Dongsheng Li and Huina Luo contributed equally to this work. 'VetCell Biotechnology Company Limited, Foshan 528225, China ${ }^{3}$ Department of Obstetrics and Gynecology, The First People's Hospital of Foshan, Foshan 528000, China

Full list of author information is available at the end of the article
}

diseases, and have important clinical significance of diagnostic and therapeutic [10].

Exosomes isolated from biological fluids such as plasma and urine hold diagnostic potential [11]. Plasmaderived exosomes (Plasma-exo), which are simple collected, have no adverse effects on health, are considered diagnostic markers for several diseases such as oncology [12], hematonosis [13], angiocardiopathy [14] or ischemic disease [15]. The study of their content (protein or nucleic acid) components is also helpful for the treatment of diseases. Urine-derived exosomes (Urine-exo) are secreted by various cells in the urinary system and released into the urine. The changes of urinary exosome-derived miRNAs and proteins can be used as

(c) The Author(s). 2021 Open Access This article is licensed under a Creative Commons Attribution 4.0 International License, which permits use, sharing, adaptation, distribution and reproduction in any medium or format, as long as you give appropriate credit to the original author(s) and the source, provide a link to the Creative Commons licence, and indicate if changes were made. The images or other third party material in this article are included in the article's Creative Commons licence, unless indicated otherwise in a credit line to the material. If material is not included in the article's Creative Commons licence and your intended use is not permitted by statutory regulation or exceeds the permitted use, you will need to obtain permission directly from the copyright holder. To view a copy of this licence, visit http://creativecommons.org/licenses/by/4.0/ The Creative Commons Public Domain Dedication waiver (http://creativecommons.org/publicdomain/zero/1.0/) applies to the data made available in this article, unless otherwise stated in a credit line to the data. 
biomarkers in kidney diseases for monitoring the changes of diseases and judging prognosis, and also have important value in the disease treatment $[16,17]$.

Mesenchymal stem cells (MSCs) have emerged as a promising therapeutic strategy for several diseases. There is accumulating evidence suggesting their therapeutic effects are largely mediated by paracrine factors including cytokines, growth factors, and exosomes [18, 19]. Numerous studies have revealed that MSC-derived exosomes (MSC-exo) might represent a novel cell-free therapy with compelling advantages over MSCs such as lower immunogenicity and no tumorigenicity [20-23].

In recent years, natural or artificially engineered exosomes as new carriers for drug delivery in clinics, have a good development prospect. It is particularly important to establish a fast, simple and stable separation method for the research and application of exosomes [24, 25]. The isolation and identification methods of different tissues-derived exosomes from dogs [26], horses [27] and cattle [28] samples have been established, but the exosomes from feline samples have been rarely reported. The objective of this study was to develop an efficient and robust method for MSC-exo, Plasma-exo and Urine-exo from feline samples (Fig. 1). This study provides comprehensive techniques such as transmission electron microscopy, flow nano analysis and western blotting to identify and characterize exosomes, allowing them to be quantified and sized, as well as characterized through specific morphology and a distinct protein expression.

\section{Results}

Identification of adipose-derived mesenchymal stem cells (AD-MSCs)

\section{Differentiation of AD-MSCS}

After induction with adipogenic medium for 14 days, AD-MSCs gradually changed from fibroblast-like cells to flattened cells, and many different sizes lipid droplets appeared in the cytoplasm. Cellular staining was positive and the multiple lipid droplets in differentiated cells were stained red by staining with Oil red-O. After incubation with osteogenic medium for 5 days, MSCs exhibited obvious morphological alterations. Calcium nodules appeared on the 10th day of induced differentiation and tightly packed colonies forming nodule-like structures were observed and deposition of calcium in these cells was observed by staining with alizarin red (Fig. 2A).

\section{Flow cytometry analysis of AD-MSCs}

$A D-M S C s$ were highly-expressed mesenchymal stem cell surface markers CD44, CD90 and CD105, while for the lowly-expressed haematopoietic stem cells surface markers CD34, leukocyte common antigen CD45 and major histocompatibility complex class II HLA-DR (Fig. 2B). That is, the isolated and cultured cells conformed the characteristics and identification criteria of mesenchymal stem cells.

\section{Transmission electron microscopy (TEM)}

TEM confirmed 3 different soures-derived exosomes showed the cup-shaped spherical morphology with of

Cell Culture Medium, $\mathbf{5 0} \mathbf{~ m l}$
$300 \times g, 10 \mathrm{~min}$ Dead Cells




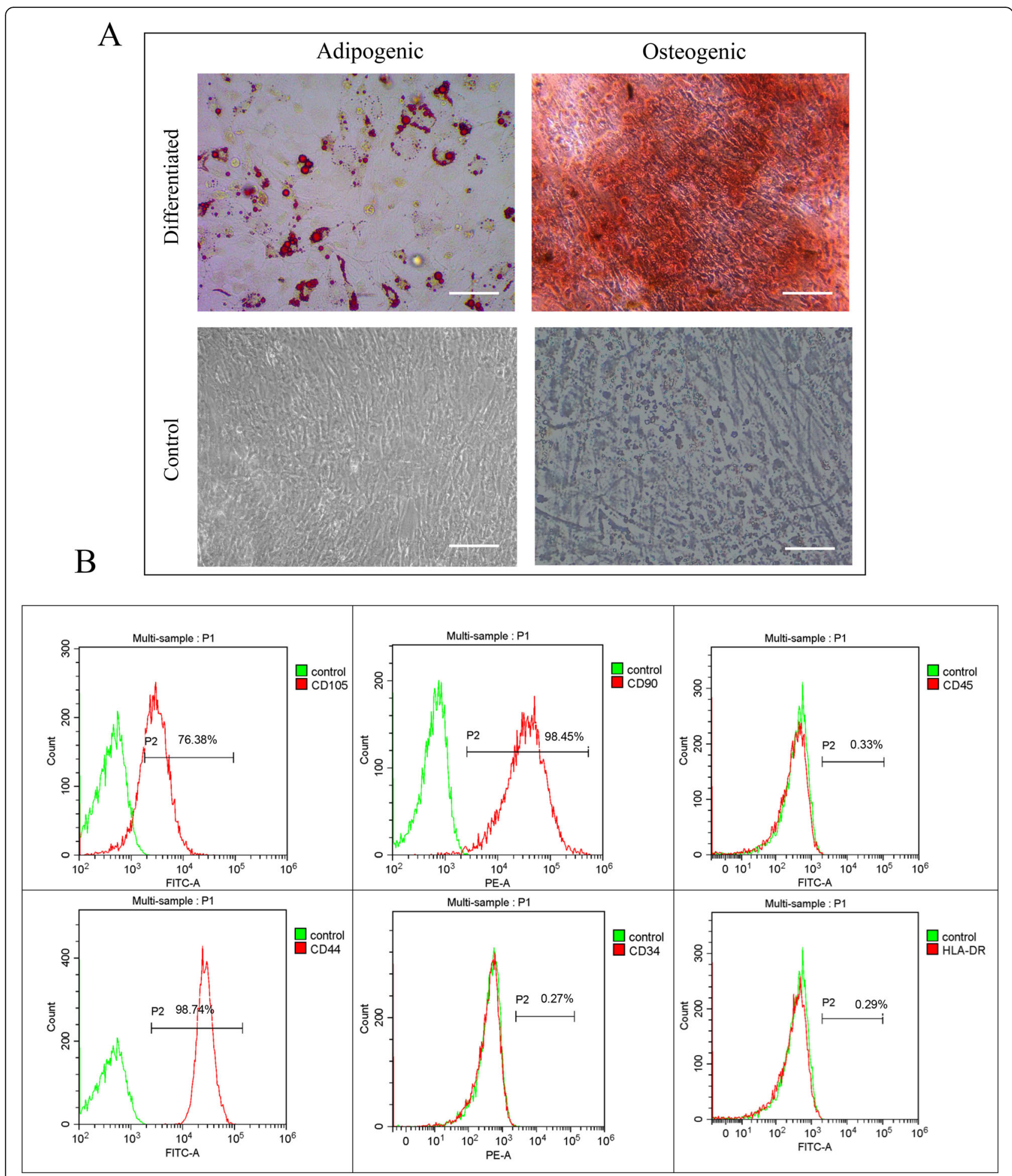

Fig. 2 Identification of feline adipose-derived mesenchymal stem cells. A Adipogenic and osteogenic differentiation of feline AD-MSCs. AD-MSCS were positive for Oil red-O staining and alizarin red staining. Scale bars, $50 \mu \mathrm{m}$. B Surface markers of feline AD-MSCs. Based on flow cytometric analysis, surface molecule markers CD44, CD90, and CD105 were highly expressed on feline AD-MSCs, whereas the expression of hematopoietic stem cell markers CD34, leukocyte common antigen CD45, and major histocompatibility complex HLA-DR were rarely expressed 
exosomal vesicles that are concave in the middle (Fig. 3). The vesicles observed ranged in size from 30 to $100 \mathrm{~nm}$.

\section{Flow nano analyzer}

The exosomes from MSCs cell culture medium, plasma, and urine exhibited an ideal mean diameter of $74.76 \mathrm{~nm}$, $66.62 \mathrm{~nm}$, and $72.88 \mathrm{~nm}$, a concentration of $2.62 \times 10^{10}$ $/ \mathrm{ml}, 6.42 \times 10^{10} / \mathrm{ml}$, and $8.49 \times 10^{11} / \mathrm{ml}$, as detected by Flow NanoAnalyzer (Fig. 4).

\section{Western blotting}

Our analysis revealed detection of four surface-marker proteins (TSG101, CD9, CD63, and CD81), with results showing all samples isolated by our ultrafiltration technique were positive for TSG101, CD9, CD63, and CD81, indicating the presence of exosomal marker proteins (Fig. 5 and Additional file 1).

\section{Discussion}

Exosomes are released by virtually every cell type in the body cells into biological fluids in vivo and cell culture conditioned media in vitro $[29,30]$. Exosomes have been shown to be key mediators of cell to cell communication, delivering a distinct cargo of lipids, proteins and nucleic acids that reflects their cell of origin [31, 32]. As a new biomarker, exosomes have been widely used in the diagnosis and therapeutics of human diseases, but there are few researches in related fields of pet medical. The research interest in exosomes is continuously increasing however the lack of standard methods for isolation and quantification, limits the reliability and reproducibility of exosome use [33, 34].

This study provided a method based on differential centrifugation of exosome isolation for 3 different biofluids from feline samples, laying a foundation for the application of exosomes in disease diagnosis and treatment of pet cats in the future. The differential centrifugation method is based on the difference in size and density between the exosome sample and other substances, through a series of centrifuges with different centrifugal forces and different centrifugal time lengths, non-exosomes are gradually removed after precipitation, and then exosomes are precipitate by ultracentrifugation and re-suspended finally [35, 36]. Ultracentrifugation is the most widely used method for exosome isolation and was once called the "gold standard" for exosome preparation [37, 38]. Due to its simple operation and stable separation effect, about more than half of exosomes related researcher used this method to extract exosomes [39].

In this study, the ultrastructure, particle size and surface markers of exosomes were identified by transmission electron microscopy, flow nano analyzer and western blot. The results showed that the three exosomes were round or elliptic vesicles with membranous structures around the vesicles, similar in shape to those previously described in mammals. The particle size of Urine-exo detected by flow nano analyzer is the largest of the three exosome samples, while Plasma-exo is the smallest, but all within the range of $30-100 \mathrm{~nm}$. Compared to plasma and urine samples, the number of exosomes found in MSCs cell culture medium was significantly lower. This may be because the volume of $50 \mathrm{ml}$ cell culture medium is too small, and a larger volume of medium is needed to obtain higher production of exosomes. Tetraspanins (including CD81, CD63 and CD9 protein) are common exosomal specific markers for extracellular vesicles such as exosomes and were suggested by the International Society of Extracellular Vesicles (ISEV) for the identification of exosomes [27]. As a cytosolic protein, Tumor Susceptibility Gene 101 (Tsg101) is involved in multivesicular body formation of exosome, is considered to be another important exosome marker [40]. Our western blotting result showed that the marker proteins were detected to be all positive in exosomes from 3 different biofluids. But all proteins signal strengths of MSC-exo are weaker than those in the serum and urine, probably because number of
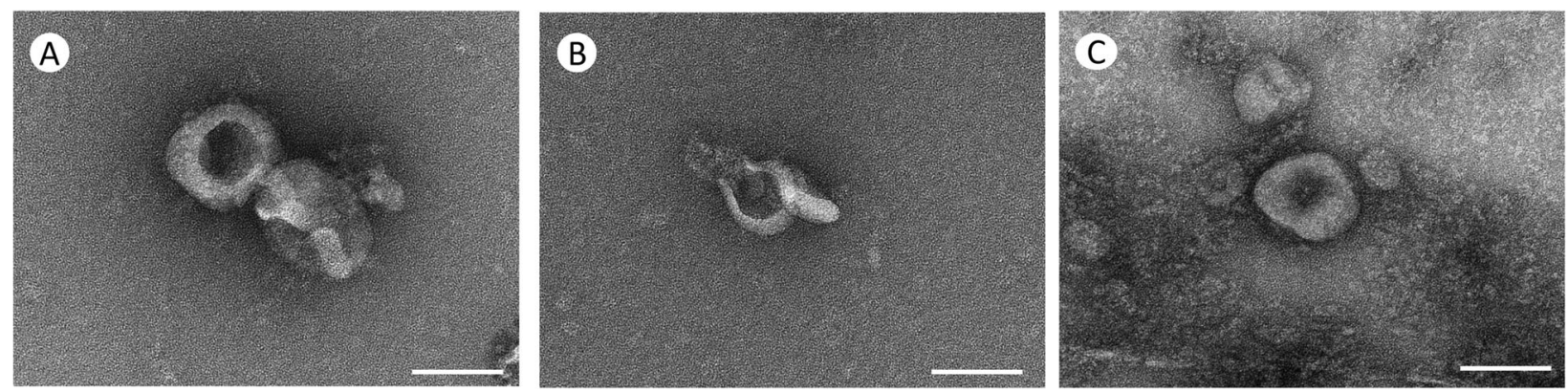

Fig. 3 Transmission electron microscopy of exosomes from feline samples. A representative TEM image of isolated exosomes from feline adiposederived mesenchymal stem cell culture medium(A), from feline plasma (B), and from feline urine (C). Exosomes isolated by differential ultracentrifugation were cup-shaped and in size from 30 to $100 \mathrm{~nm}$ 

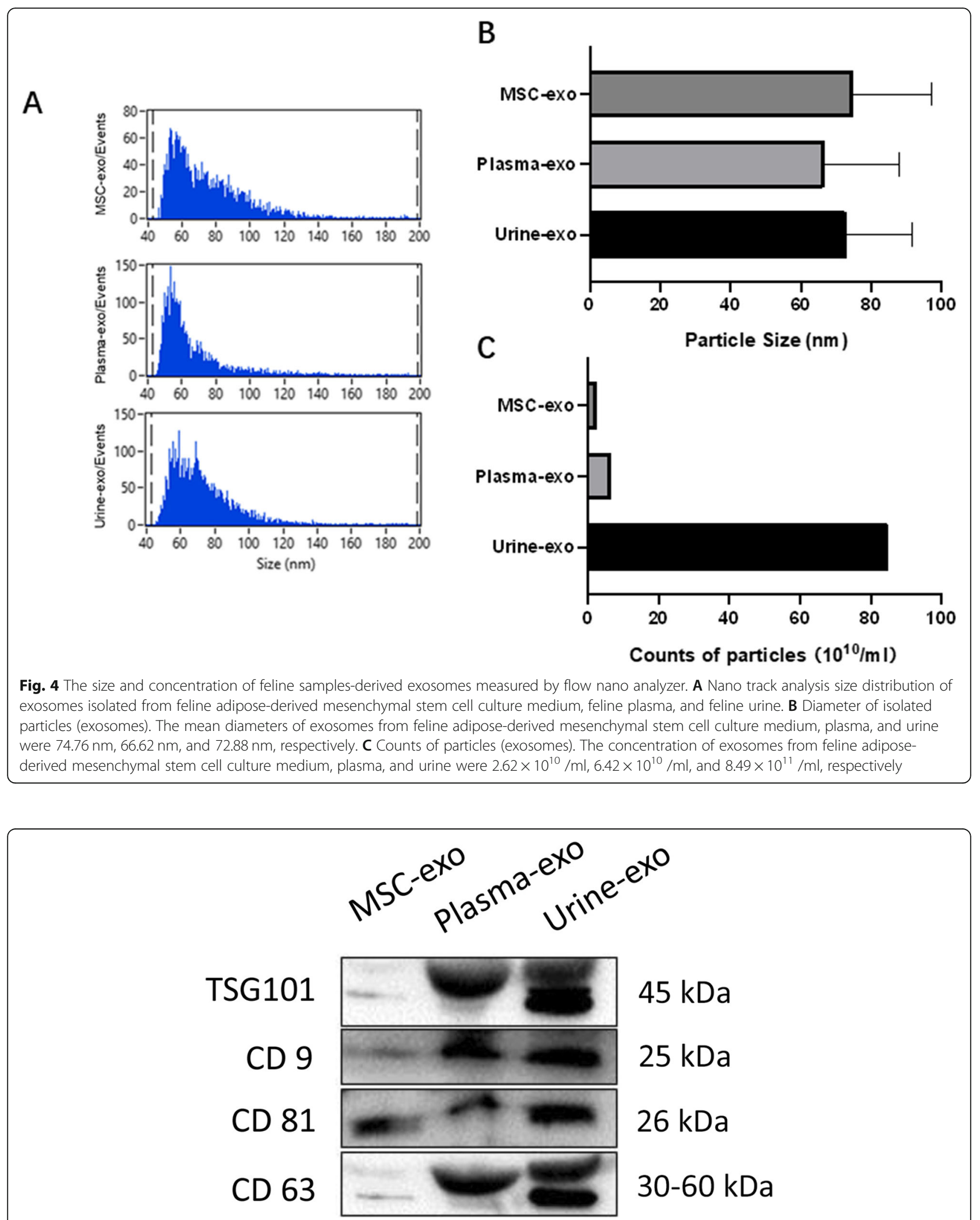

Fig. 5 Western blotting analysis of exosomes from feline samples with anti-TSG101, anti-CD9, anti-CD63, and anti-CD81. Surface Markers TSG101, CD9, CD63, and CD81 positively expressed in exosomes secreted from feline adipose-derived mesenchymal stem cell culture medium, plasma, and urine 
exosomes are fewer of them. Therefore, combined with the above results, it is demonstrated that the methods of exosome isolation we established is feasible and effective, allowing nanoparticles to be analysed in downstream applications.

\section{Conclusions}

Overall, our results evidence the feasibility to easily isolate exosome from the supernatants of feline adipose derived mesenchymal stem cells, as well as from plasma and urine of feline. This method for isolating exosomes from feline samples can be used to further diagnosis and therapeutics in veterinary pre-clinical and clinical studies.

\section{Methods}

Isolation, culture and identification of adipose-derived mesenchymal stem cells

Abdominal subcutaneous adipose tissues were collected aseptically at Affiliated Animal Hospital, Department of Veterinary Medicine of Foshan University. The tissues were cut into tissue blocks about $1 \mathrm{~mm}^{2}$ in size and were digested with $1 \mathrm{mg} / \mathrm{mL}$ collagenase type $\mathrm{I}$ at $37^{\circ} \mathrm{C}$ for 2 $\sim 3 \mathrm{~h}$. The digestive juices were filtered with 200-mesh cell strain and centrifuged at $800 \times \mathrm{g}$ for $5 \mathrm{~min}$ to collect AD-MSCs. Approximately 5000 isolated suspended cells per $\mathrm{cm}^{2}$ were transferred to cell culture flask (Corning, USA) in Dulbecco's Modified Eagle's Medium supplemented with $10 \%$ exosome-free Fetal Bovine Serum (FBS, Biological Industries, Israel), 1\% Pen-Strep (Gibco, USA), and 1\% L-glutamine (Gibco, USA) and placed into the incubator at $37^{\circ} \mathrm{C}$ in a humidified incubator containing $5 \% \mathrm{CO}_{2}$. After $24 \mathrm{~h}$, the medium was replaced for the first time to remove most of the blood cells and replaced every $3 \mathrm{~d}$ thereafter. AD-MSCs were digested with $0.25 \%$ trypsin and passaged routinely when $80 \sim$ $90 \%$ confluence was reached.

The AD-MSCs were characterized by multipotential differentiation and flow cytometry analysis. In vitro adipogenic and osteogenic differentiation were examined using MSCs Adipogenic Differentiation Kit (Cyanogen, China) and MSCs Osteogenic Differentiation Kit (Cyanogen, China) following the manufacturer's protocol for each kit. Cells were stained with Oil Red O solution to assess adipogenic differentiation and alizarin red solution to assess osteogenic differentiation.

Flow cytometry analysis was performed using a CytoFLEX flow cytometry instrument (Beckman, USA). Data acquisition and analysis was performed with CytExpert (Beckman, USA). Briefly, AD-MSCs of passage 2 were stained for $30 \mathrm{~min}$ with FITC -conjugated or phycoerythrin $(\mathrm{PE})$-conjugated monoclonal antibodies at $37^{\circ} \mathrm{C}$. The following monoclonal antibodies were used: anti-CD34PE (cat.no.ab23830; Abcam), anti-CD44- FITC
(cat.no.MA1-10229; Invitrogen), anti-CD45-FITC (cat.no.ab27287; Abcam), anti-CD90-PE (cat.no.11-0900-81; Invitrogen), anti-CD105-FITC (cat.no.ab11415; Abca$\mathrm{m}$ ), and anti-HLA-DR-FITC (cat.no. L243-347400; BD Biosciences). Chilled PBS was used to wash and remove unbound antibodies, and then a total of $2 \times 10^{5}$ cells from each sample tube were acquired for analysis using Flow Cytometer.

\section{Preparation of cell culture medium samples}

FBS added to the cell culture medium should be depleted of exosomes by ultracentrifugation at $120000 \mathrm{x} \mathrm{g}$ over night at $4{ }^{\circ} \mathrm{C}$ prior to use.50-80\% confluent ADMSCs at passage 2-5 were washed twice in PBS and further cultured in an exosome-free medium as described above. Briefly, cell culture medium was harvested after $48 \mathrm{~h}$ of incubation with exosome- free medium and stored at $-80^{\circ} \mathrm{C}$ for subsequent experiments.

\section{Preparation of plasma samples}

Samples were mixed from 3 female and 2 male felines presented at Affiliated Animal Hospital, Department of Veterinary Medicine of Foshan University. Blood samples are collected into acollections tubes containing anticoagulant and the cell components were removed by centrifugation $\left(800 \times \mathrm{g}, 4{ }^{\circ} \mathrm{C}, 15 \mathrm{~min}\right)$. The supernatant was diluted with phosphate buffered saline of the same volume (1:1) and stored at $-80^{\circ} \mathrm{C}$ for subsequent experiments.

\section{Preparation of urine samples}

Urine samples were mixed from 1 female and 2 male felines presented at Affiliated Animal Hospital, Department of Veterinary Medicine of Foshan University. Samples are collected into tubes and stored at $-80^{\circ} \mathrm{C}$ for subsequent experiments.

\section{Isolation of exosomes}

Exosomes were isolated by differential centrifugation. Briefly, Cell culture medium $(50 \mathrm{~mL})$ were centrifuged at $4{ }^{\circ} \mathrm{C}, 300 \times \mathrm{g}$ for $10 \mathrm{~min}$ to remove dead cells, followed by centrifuging at $12,000 \times \mathrm{g}$ for $30 \mathrm{~min}$ at $4{ }^{\circ} \mathrm{C}$ to remove cell debris. Supernatant was collected and filtered through $0.22 \mathrm{~mm}$ filters (Merck Millipore, USA) to remove contaminating microvesicles larger than $200 \mathrm{~nm}$. Following this, the filtered supernatant was transferred to new polycarbonate tubes for ultracentrifugation in ultra-speed centrifuge (Beckman Coulter XL-90, SW28Ti rotor; Beckman Coulter; USA) at $100,000 \times$ g for 70 min at $4{ }^{\circ} \mathrm{C}$ and if not completely full add PBS. Discard the supernatant. For maximal exosome retrieval, resuspend the exosome enriched pellet repeatedly in $100 \mu \mathrm{l}$ PBS. 
Diluted plasma samples $(5 \mathrm{ml})$ were centrifuged at $12,000 \times \mathrm{g}$ for $30 \mathrm{~min}$ at $4{ }^{\circ} \mathrm{C}$ to remove cell debris. Transfer the supernatant to new ultracentrifuge tubes and if not completely full add PBS. Clarified supernatant was ultracentrifuged at $50,000 \times \mathrm{g}$ for $70 \mathrm{~min}$ at $4{ }^{\circ} \mathrm{C}$ to remove large proteins and microvesicles. Following this, supernatant was ultracentrifuged at $100,000 \times \mathrm{g}$ for 70 min at $4{ }^{\circ} \mathrm{C}$. Discard the supernatant. For maximal exosome retrieval, resuspend the exosome enriched pellet repeatedly in $100 \mu \mathrm{l}$ PBS.

Urine samples $(15 \mathrm{ml})$ were centrifuged at $4{ }^{\circ} \mathrm{C}, 300 \times \mathrm{g}$ for $10 \mathrm{~min}$ to remove dead cells, followed by centrifuging at $12,000 \times \mathrm{g}$ for $30 \mathrm{~min}$ at $4{ }^{\circ} \mathrm{C}$ to remove cell debris. Transfer the supernatant to new ultracentrifuge tubes and if not completely full add PBS. Clarified supernatant was ultracentrifuged at $50,000 \times \mathrm{g}$ for $70 \mathrm{~min}$ at $4{ }^{\circ} \mathrm{C}$ in ultra-speed centrifuge remove large proteins and microvesicles. Following this, supernatant was ultracentrifuged at $100,000 \times \mathrm{g}$ for $70 \mathrm{~min}$ at $4{ }^{\circ} \mathrm{C}$. Discard the supernatant. For maximal exosome retrieval, resuspend the exosome enriched pellet repeatedly in $100 \mu \mathrm{l}$ PBS.

\section{Transmission electron microscopy (TEM)}

Exosome samples were diluted in PBS, dropped on a carbon-coated copper grid, and then stained with $1 \%$ uranyl acetate for $1 \mathrm{~min}$. Grids were imaged under a Hitachi H-7650 transmission electron microscope.

\section{Flow nano analyzer}

Exosome samples were diluted 1:100 and analyzed using the Flow Nano Analyzer (NanoFCM Inc.) according to manufacturer's protocol. Briefy, the lasers were calibrated using $200 \mathrm{~nm}$ control beads (NanoFCM Inc.), which were then analyzed as a reference for particle concentration. Additionally, a mixture of diferent sized beads (NanoFCM Inc.) was analyzed to set reference for size distribution.

\section{Western blotting}

Exosome samples were denatured in protein loading buffer (10\% sodium dodecyl sulfate (SDS), $250 \mathrm{mM}$ Tris- $\mathrm{HCl}(\mathrm{pH} 6.8), 0.5 \%$ Bromophenol blue, $50 \%$ glycerin, $5 \% \beta$-Mercaptoethanol) at $95^{\circ} \mathrm{C}$ for $10 \mathrm{~min}$. Proteins were separated by $10 \%$ sodium dodecyl polyacrylamide gel electrophoresis (SDS-PAGE), and were then transferred to polyvinylidene fluoride (PVDF) membranes (Merck Millipore, USA). The membranes were blocked with $5 \%$ non-fat milk in Tris-buffered saline containing $0.1 \%$ Tween-20 for 1 $\mathrm{h}$ at room temperature and afterwards incubated at room temperature for $1 \mathrm{~h}$ with antibodies against TSG101 (Santa Cruz, sc-7964, 1:1000), CD81 (Affinity, DF2306, 1:1000), CD63 (Santa Cruz, sc-5275, 1:
1000) and CD9 (Affinity, AF5139, 1:1000), followed by incubation with horseradish peroxidase conjugated secondary antibodies at room temperature for $1 \mathrm{~h}$. Luminescent visualizationwas done using an ECL kit (Tanon, China) to identify immunoreactive protein bands.

\section{Abbreviations}

AD-MSCs: Adipose-derived mesenchymal stem cells; FBS: Fetal bovine serum; ISEV: International society of extracellular vesicles; MSCs: Mesenchymal stem cells; MSC-exo: Mesenchymal stem cells derived exosomes; Plasmaexo: Plasma derived exosomes; PVDF: Polyvinylidene fluoride; SDS: Sodium dodecyl sulfate; Tsg101: Tumor susceptibility gene 101; Urine-exo: Urine derived exosomes

\section{Supplementary Information}

The online version contains supplementary material available at https://doi. org/10.1186/s12917-021-02960-4

Additional file 1. Western blot instructions and original images.

\section{Acknowledgements}

Not applicable.

Authors' contributions

BYW and YX designed the study. DSL, HNL and HMR performed the experiments and analysed the data. ZSC and SFC collected the samples. All authors read and approved the final manuscript.

\section{Funding}

This study was supported by grants from the Natural Science Foundation of Guangdong Province (no. 2020A1515011110).

Availability of data and materials

The datasets used and/or analysed during the current study are available from the corresponding author upon reasonable request.

\section{Declarations}

\section{Ethics approval and consent to participate}

All procedures in the present study were approved by the Animal Ethics Committee of Foshan University (decision number: FSUeae2020102). and written informed consent was obtained from all donors.

Consent for publication

Not applicable.

\section{Competing interests}

The authors declare that they have no competing interests.

\section{Author details}

${ }^{1}$ VetCell Biotechnology Company Limited, Foshan 528225, China. ${ }^{2}$ School of Life Science and Engineering, Foshan University, Foshan 528225, China.

${ }^{3}$ Department of Obstetrics and Gynecology, The First People's Hospital of Foshan, Foshan 528000, China.

Received: 21 January 2021 Accepted: 7 July 2021

Published online: 12 August 2021

\section{References}

1. Muller L, Hong CS, Stolz DB, Watkins SC, Whiteside TL. Isolation of biologically-active exosomes from human plasma. J Immunol Methods. 2014:411:55-65.

2. Nonaka T, Wong D. Saliva-exosomics in cancer: molecular characterization of cancer-derived exosomes in saliva. Enzymes. 2017;42:125-51.

3. Manek R, Moghieb A, Yang Z, Kumar D, Kobessiy F, Sarkis GA, et al. Protein biomarkers and Neuroproteomics characterization of microvesicles/ 
Exosomes from human cerebrospinal fluid following traumatic brain injury. Mol Neurobiol. 2018;55(7):6112-28.

4. Liu Z, Cauvi DM, Bernardino E, Lara B, Lizardo RE, Hawisher D, et al. Isolation and characterization of human urine extracellular vesicles. Cell Stress Chaperones. 2018;23(5):943-53.

5. Munagala R, Aqil F, Jeyabalan J, Gupta RC. Bovine milk-derived exosomes for drug delivery. Cancer Lett. 2016;371(1):48-61.

6. Barcelo M, Castells M, Bassas L, Vigues F, Larriba S. Semen miRNAs contained in Exosomes as non-invasive biomarkers for prostate Cancer diagnosis. Sci Rep. 2019;9(1):13772.

7. Zhao Y, XU J. Synovial fluid-derived exosomal IncRNA PCGEM1 as biomarker for the different stages of osteoarthritis. Int Orthop. 2018;42(12):2865-72.

8. Urbanelli L, Buratta S, Sagini K, Ferrara G, Lanni M, Emiliani C. Exosomebased strategies for diagnosis and therapy. Recent Pat CNS Drug Discov. 2015:10(1):10-27.

9. Wortzel I, Dror S, Kenific CM, Lyden D. Exosome-mediated metastasis: communication from a distance. Dev Cell. 2019:49(3):347-60.

10. He C, Zheng S, Luo Y, Wang B. Exosome Theranostics: biology and translational medicine. Theranostics. 2018:8(1):237-55.

11. Lin J, Li J, Huang B, Liu J, Chen X, Chen XM, et al. Exosomes: novel biomarkers for clinical diagnosis. ScientificWorldJournal. 2015;2015:657086.

12. Tomasetti M, Lee W, Santarelli L, Neuzil J. Exosome-derived microRNAs in cancer metabolism: possible implications in cancer diagnostics and therapy. Exp Mol Med. 2017:49(1):e285.

13. Nomura S. Extracellular vesicles and blood diseases. Int J Hematol. 2017; 105(4):392-405.

14. Lawson C, Vicencio JM, Yellon DM, Davidson SM. Microvesicles and exosomes: new players in metabolic and cardiovascular disease, vol. 228; 2016.

15. Otero-Ortega L, Gomez DFM, Laso-Garcia F, Rodriguez-Frutos B, MedinaGutierrez E, Lopez JA, et al. Exosomes promote restoration after an experimental animal model of intracerebral hemorrhage. J Cereb Blood Flow Metab. 2018;38(5):767-79.

16. Street JM, Koritzinsky EH, Glispie DM, Star RA, Yuen PS. Urine Exosomes: an emerging trove of biomarkers. Adv Clin Chem. 2017;78:103-22.

17. Grange C, Papadimitriou E, Dimuccio V, Pastorino C, Molina J, O'Kelly R, et al. Urinary extracellular vesicles carrying Klotho improve the recovery of renal function in an acute tubular injury model. Mol Ther. 2020;28(2):490502.

18. Dongsheng L, Zhisheng C, Shengfeng C, Huiqin J, Xiaoshu Z, Dongzhang L, et al. Chicken Mesenchymal Stem Cells as Feeder Cells Facilitate the Cultivation of Primordial Germ Cells from Circulating Blood and Gonadal Ridge. Stem Cell Discov. 2019;9(1):1-14.

19. Gnecchi M, Danieli P, Malpasso G, Ciuffreda MC. Paracrine mechanisms of Mesenchymal stem cells in tissue repair. Methods Mol Biol. 2016;1416:12346.

20. Wu P, Zhang B, Shi H, Qian H, Xu W. MSC-exosome: a novel cell-free therapy for cutaneous regeneration. Cytotherapy. 2018;20(3):291-301.

21. Phinney DG, Pittenger MF. Concise review: MSC-derived Exosomes for cellfree therapy. Stem Cells. 2017;35(4):851-8.

22. Yu B, Zhang X, Li X. Exosomes derived from mesenchymal stem cells. Int J Mol Sci. 2014;15(3):4142-57.

23. Alonso-Alonso ML, Garcia-Posadas L, Diebold Y. Extracellular vesicles from human adipose-derived Mesenchymal stem cells: a review of common cargos. Stem Cell Rev Rep. 2021. Online ahead of print.

24. Ludwig N, Whiteside TL, Reichert TE. Challenges in Exosome Isolation and Analysis in Health and Disease. Int J Mol Sci. 2019;20(19):4684.

25. Yue B, Yang H, Wang J, Ru W, Wu J, Huang Y, et al. Exosome biogenesis, secretion and function of exosomal miRNAs in skeletal muscle myogenesis. Cell Prolif. 2020;53(7):e12857.

26. Aguilera-Rojas M, Badewien-Rentzsch B, Plendl J, Kohn B, Einspanier R. Exploration of serum- and cell culture-derived exosomes from dogs. BMC Vet Res. 2018;14(1):179.

27. Klymiuk MC, Balz N, Elashry Ml, Heimann M, Wenisch S, Arnhold S Exosomes isolation and identification from equine mesenchymal stem cells. BMC Vet Res. 2019;15(1):42.

28. Yamauchi M, Shimizu K, Rahman M, Ishikawa H, Takase H, Ugawa S, et al. Efficient method for isolation of exosomes from raw bovine milk. Drug Dev Ind Pharm. 2019;45(3):359-64.

29. Hessvik NP, Llorente A. Current knowledge on exosome biogenesis and release. Cell Mol Life Sci. 2018;75(2):193-208.
30. Tran P, Xiang D, Tran T, Yin W, Zhang Y, Kong L, et al. Exosomes and Nanoengineering: a match made for precision therapeutics. Adv Mater. 2020;32(18):e1904040.

31. Mathivanan S, Ji H, Simpson RJ. Exosomes: extracellular organelles important in intercellular communication. J Proteome. 2010;73(10):1907-20.

32. Ratajczak MZ, Ratajczak J. Extracellular microvesicles/exosomes: discovery, disbelief, acceptance, and the future? Leukemia. 2020;34(12):3126-35.

33. Soares MT, Catita J, Martins RI, A BDCE, Henriques AG. Exosome isolation from distinct biofluids using precipitation and column-based approaches. PLoS One. 2018;13(6):e198820.

34. Yamashita T, Takahashi Y, Takakura Y. Possibility of exosome-based therapeutics and challenges in production of Exosomes eligible for therapeutic application. Biol Pharm Bull. 2018;41(6):835-42.

35. Helwa I, Cai J, Drewry MD, Zimmerman A, Dinkins MB, Khaled ML, et al. A comparative study of serum exosome isolation using differential ultracentrifugation and three commercial reagents. PLoS One. 2017;12(1): e170628.

36. Chen QG, Chen L, Zhong QH, Zhang L, Jiang YH, Li SQ, et al. Optimization of urinary small extracellular vesicle isolation protocols: implications in early diagnosis, stratification, treatment and prognosis of diseases in the era of personalized medicine. Am J Transl Res. 2020;12(10):6302-13.

37. Doyle LM, Wang MZ. Overview of Extracellular Vesicles, Their Origin, Composition, Purpose, and Methods for Exosome Isolation and Analysis. Cells Basel. 2019;8(7):727.

38. Coughlan C, Bruce KD, Burgy O, Boyd TD, Michel CR, Garcia-Perez JE, et al. Exosome isolation by ultracentrifugation and precipitation and techniques for downstream analyses. Curr Protoc Cell Biol. 2020;88(1):e110.

39. Kurian TK, Banik S, Gopal D, Chakrabarti S, Mazumder N. Elucidating methods for isolation and quantification of Exosomes: a review. Mol Biotechnol. 2021;63(4):249-66.

40. Koritzinsky EH, Street JM, Chari RR, Glispie DM, Bellomo TR, Aponte AM, et al. Circadian variation in the release of small extracellular vesicles can be normalized by vesicle number or TSG101. Am J Physiol Renal Physiol. 2019; 317(5):F1098-110.

\section{Publisher's Note}

Springer Nature remains neutral with regard to jurisdictional claims in published maps and institutional affiliations.

Ready to submit your research? Choose BMC and benefit from

- fast, convenient online submission

- thorough peer review by experienced researchers in your field

- rapid publication on acceptance

- support for research data, including large and complex data types

- gold Open Access which fosters wider collaboration and increased citations

- maximum visibility for your research: over $100 \mathrm{M}$ website views per year

At $\mathrm{BMC}$, research is always in progress.

Learn more biomedcentral.com/submissions 